\title{
Communication of results of necropsies in North East Thames region
}

\author{
Paula Whitty, Christopher Parker, Fatima Prieto-Ramos, Salim Al-Kharusi
}

\section{Abstract}

Objective-To evaluate the adequacy of reporting of results of necropsy to referring clinicians and to general practitioners.

Design-Questionnaire survey of referring clinicians and general practitioners of deceased patients in four districts in North East Thames region. Patients were selected by retrospective systematic sampling of $\mathbf{5 0}$ or more necropsy reports in each district.

Setting-One teaching hospital, one inner London district general hospital, and two outer London district general hospitals.

Participants -70 consultants and 146 general practitioners who were asked about 214 necropsy reports; coroners' reports were excluded.

Main outcome measures-Time taken for dispatch of final reports after necropsy, consultants' recognition of the reports, general practitioners' recognition of the reports or of their findings, and consultants' recall of having discussed the findings with relatives.

Results-Only two hospitals dispatched final reports including histological findings (mean time to dispatch 144 days and 22 days respectively). 42 $(60 \%)$ consultants and $83(57 \%)$ general practitioners responded to the survey. The percentage of reports seen by consultants varied from $37 \%(n=13)$ to $87 \%$ $(n=36)$; in all, only $47 \%(39 / 83)$ of general practitioners had been informed of the findings by any method. Consultants could recall having discussed findings with only $42 \%(47 / 112)$ of relatives.

Conclusions-Communication of results of necropsies to hospital clinicians, general practitioners, and relatives is currently inadequate in these hospitals.

Implications and action-A report of the macroscopic findings should be dispatched immediately after necropsy to clinicians and general practitioners; relatives should routinely be invited to discuss the necroscopic findings. One department has already altered its practice.

\section{Introduction}

A joint working party of the Royal College of Pathologists, the Royal College of Physicians, and the Royal College of Surgeons on the use of necropsies in audit identified communication between pathologists and clinicians as an important problem and also highlighted likely problems for general practitioners and relatives.' Information obtained at necropsy is not being used as it might be for audit, owing to inadequate feedback from pathologists. ${ }^{2-5}$ The negative effect of poor communication to clinicians may have contributed to the general decline in necropsy rates. ${ }^{6}$ A recent survey in North East Thames uncovered frequent complaints from clinicians about delayed or absent final necropsy reports. The notification of patients' deaths to general practitioners has been shown to be inadequate, ${ }^{8}$ but there have been no previous audits of the communication of the results of necropsies.

The current systems for reporting the results of necropsy in hospitals in the United Kingdom vary. Most hospitals produce a final report, containing both macroscopic and histological findings; some provide interim oral or brief written reports, and demonstrations to clinicians of diseased organs and "mortality meetings" attended by both clinicians and pathologists may occur. General practitioners may receive the findings of the necropsy in the final summary or receive a copy of the necropsy report.

This study was designed to explore the adequacy of communication of necropsy results to referring clinicians and to general practitioners in North East Thames region.

\section{Subjects and methods}

We selected four districts in North East Thames, representing districts containing a teaching hospital, an inner London district general hospital, and two outer London district general hospitals. We obtained a systematic retrospective sample of 50 consecutive necropsy reports from the files of the pathology departments of these hospitals. Coroners' necropsies were not part of this sampling frame. No attempt was made to include them in the sample because they do not fit easily into the lines of communication among the hospital consultants, pathologists, and general practitioners under study. The dates of death, necropsy, and dispatch of the final report were identified from the reports. Referring clinicians were identified from the reports, and the patients' general practitioners were identified from hospital records. Appropriate ethical committee consent was obtained.

Copies of the necropsy reports were sent with a 응 questionnaire to the clinicians and general practi- No tioners previously responsible for the care of the deceased patients. Clinicians were asked whether they had previously seen the reports and if so when. They were also asked to recall whether they had informed general practitioners and relatives of the results of the necropsy. Their opinions were also canvassed on who should be responsible for informing relatives, on the uses of necroscopic findings, and on the usual delays experienced. Consultants who failed to respond were telephoned on at least two occasions. General practitioners were asked if they had received the findings contained in the report in any format, whether they had seen the relatives about the results of the necropsy and, if so, how adequate for counselling was the information they had received. Their opinions on the 8 usefulness of information obtained at necropsy were also sought. Non-responders were telephoned by the survey team on at least two occasions.

We had hoped to obtain the views of relatives of deceased patients about their experience of receiving information about the necropsy, but issues relating to 
confidentiality of information could not be resolved in the time available for this project.

\section{Results}

All four districts had problems with retrieval of medical records for our study either manually or through the hospital's patient administration system, albeit to different degrees. Files were commonly absent from the system and, even when present, were incomplete and contained inaccuracies. Forty two out of 70 consultants $(60 \%)$ finally responded to the questionnaire, and 83 out of 146 general practitioners $(57 \%)$. All hospital specialties were represented among the responding consultants.

Examination of the sample of necropsy reports showed that districts A and B sent final necropsy reports, including the results of histological examination, and districts C and D sent only reports of macroscopic findings. The pathologist in district $\mathrm{D}$ dictated the findings immediately after the necropsy, and the report was dispatched the same day. The average time taken to dispatch a final report was extremely long in district A ( 144 days) but only 22 days in district $\mathrm{B}$ (table I). The pathologist in district D

TABLE I-Mean time from death to necropsy and mean, median, and range time to dispatch reports according to dates on reports for four districts in North East Thames region

\begin{tabular}{lcc}
\hline $\begin{array}{l}\text { District } \\
\text { (No of reports) }\end{array}$ & $\begin{array}{c}\text { Mean time from } \\
\text { death to necropsy } \\
\text { (days) }\end{array}$ & $\begin{array}{c}\text { Mean } \\
\text { (median) [range] time } \\
\text { (days) from necropsy } \\
\text { to dispatch of reports }\end{array}$ \\
\hline A $(n=50)$ & $3 \cdot 81$ & $144 \cdot 33(138)[30-274]$ \\
$B(n=50)$ & $3 \cdot 08$ & $22 \cdot 24(17)[7-61]$ \\
C $(n=64)$ & $3 \cdot 33$ & $14 \cdot 52(15)[0-45]$ \\
$D(n=50)$ & $2 \cdot 79$ & 0 (same day) \\
\hline
\end{tabular}

consistently dispatched reports of the macroscopic findings the same day whereas the pathologist in district $\mathrm{C}$ took an average of 14 days. According to the questionnaire, when shown the final reports of the necropsies of their deceased patients consultants in districts $\mathrm{A}$ and $\mathrm{D}$ remembered having seen fewer than half of them (table II). There were no obvious organisa-

TABLE II - Percentage (number) of necropsy reports seen by responding consultants and percentage (number) of responding general practitioners who had been informed of necropsy results by either final summary or copy of report

\begin{tabular}{lccccc}
\hline & \multicolumn{2}{c}{ Consultants } & & \multicolumn{2}{c}{ General practitioners } \\
\cline { 2 - 3 } District & No responding & $\begin{array}{c}\%(\mathrm{No}) \\
\text { reports seen }\end{array}$ & No responding & $\begin{array}{c}\%(\text { No) } \\
\text { informed }\end{array}$ \\
\hline A & 18 & $37(13)$ & & 10 & $40(4)$ \\
B & 12 & $87(29)$ & & 26 & $42(11)$ \\
C & 7 & $87(36)$ & & 32 & $59(19)$ \\
D & 5 & $47(8)$ & & 15 & $33(5)$ \\
\hline Total & 42 & $59(86)$ & 83 & $47(39)$ \\
\hline
\end{tabular}

TABLE III - Percentage (number) of deaths for which relatives wer informed of results of necropsy, according to responding consultants, by specialty

\begin{tabular}{lcc}
\hline & $\begin{array}{c}\%(\text { No) } \\
\text { with } \\
\text { deaths }\end{array}$ & $\begin{array}{c}\text { relatives } \\
\text { informed }\end{array}$ \\
\hline $\begin{array}{l}\text { Surgery } \\
\text { Medicine }\end{array}$ & 19 & $32(6)$ \\
Obstetrics & 19 & $31(23)$ \\
\hline Total & 112 & $42(18)$ \\
\hline
\end{tabular}

tional differences that we could identify to explain this discrepancy. Only $47 \%$ (39/83) of general practitioners patients studied either as a final summary or as the full report (table II).

The consultants were aware of only $42 \%$ of deaths (47/112) in which the relatives had been informed of the findings (table III). The numbers of consultants in individual specialties were too small to permit any conclusions regarding variation among specialties. Of the 32 general practitioners who felt sufficiently informed to counsel relatives, most $(23,72 \%)$ had seen the necroscopic findings in some form. This contrasts with 38 general practitioners who felt insufficiently had received necropsy findings in any format for the informed, of whom a minority $(11,29 \%)$ had seen the findings in some form. Thirteen general practitioners failed to answer this question.

Responding consultants believed that the necroscopic findings were useful for confirming diagnoses $(40,95 \%)$, postgraduate education $(37,88 \%)$, and medical audit $(34,81 \%)$. Only $28(66 \%)$ of consultants thought they were useful for counselling relatives, which contrasted with $81(98 \%)$ of general practitioners. General practitioners were also interested in the findings for confirming diagnoses $(80,96 \%)$. In the open section of the questionnaire $43(52 \%)$ of the responding general practitioners recorded that they should routinely be informed about the necroscopic findings on their deceased patients in some way.

\section{Discussion}

The response rates for both questionnaires were poor despite the efforts made by the survey team to improve them. Analysing a sample of non-responders was not possible within the time available for the study. However, there was no obvious relation between specialty and non-response among the hospital consultants. For the general practitioners the poor response rate may, by overrepresenting enthusiastic practitioners, overestimate the interest in necroscopic findings among general practitioners. As this interest was almost unanimous, however, it is likely to be real.

The joint working party on necropsies suggested that all final reports should be dispatched within 21 days after the examination.' This was almost achieved in district $\mathrm{B}$ but not in the three other districts audited. Similar common delays in sending laboratory reports were recently found in a pilot study on accreditation of pathology laboratories, as well as generally poor liaison between pathologists and clinicians. ${ }^{9}$

The principal reason for the current delays seems to be the slow processing of the specimens taken for histological examination, which tend to lose out in competition for laboratory time with surgical specimens. If histological examination of much material obtained at necropsy is to remain routine pathology departments must examine their organisation as a speedier turnaround of specimens is likely to require more staff. Pathologists should also reconsider whether histological examination is always necessary, or necessary on as many tissues.

The pathologist's interim report (oral or written) usually contains only information relating to the immediate cause of death. Even if the remainder of our recommendations are not implemented pathologists should at least ensure that this report is typed and dispatched immediately to both the referring clinician and the general practitioner. For self audit, however, general practitioners may also like to see information on longstanding disease, which may not be related to the direct cause of death and therefore not contained in the current interim reports.

A possible intermediate solution is to increase the detail contained in the interim report. Some pathologists dictate the complete macroscopic findings either during the examination or immediately afterwards, and a typed report is dispatched to the requesting clinicians within 24 hours. This will contain an equivalent amount of information on macroscopic findings to that in the current final reports. This is a standard to which others should aspire, although limited resources, especially of secretarial skills, make this hard to achieve. When necessary a histological report should follow subsequently. The likely objection from pathologists to this change in practice will be the resulting decline in histological examinations performed on necroscopic specimens. This has implications for training of registrars and senior registrars in 
pathology. Implementation of this recommendation would therefore have to include discussions of clinical indications for histological examinations, as mentioned earlier, and of training requirements. The criteria generated for histological examination should be agreed with the hospital clinicians.

General practitioners want information on necroscopic findings for counselling relatives and monitoring their own diagnostic ability. As relatives are usually seen fairly quickly after bereavement general practitioners need to know at least that a necropsy has taken place and that they can expect results within a short time. Systems for informing general practitioners should be reviewed to ensure that they are rapid, and general practitioners should be routinely informed of the occurrence of a necropsy or otherwise. The form requesting the necropsy should include the general practitioner's name, which should then be added to the report by the pathologist. At the minimum, the typed interim report containing information on the direct cause of death should be dispatched immediately to the general practitioner by the pathologist. Preferably, however, the more detailed report of macroscopic findings that we suggest should be copied immediately to general practitioners. Such a system is more likely to work reliably if the pathologist's secretary dispatches the report to the general practitioner and hospital clinician simultaneously, a system facilitated by including the general practitioner's name on the requests and reports. We strongly recommend that automatic dispatch of the improved report to general practitioners is implemented by all hospital pathology departments.

Although we obtained only limited information on communication of results to relatives, more than half of the relatives of the patients studied were unlikely to have been informed of the findings. The proportion differed greatly among specialties, with one or two having policies for informing relatives, notably departments of obstetrics. Bereaved relatives who suffer guilt and self reproach are at greater risk of subsequently developing psychiatric illness. ${ }^{11}$ In a study of lay perceptions of the results of necropsy $88 \%$ of relatives were reassured about the adequacy of medical care and benefited from explanations of their deceased relative's illness. ${ }^{12}$ With better communication by hospital pathologists and clinicians general practitioners could play a larger part in explaining the deceased's illness to relatives. ${ }^{10}$

Relatives should always be offered the opportunity to discuss the necroscopic findings, either with the hospital clinician or with their general practitioner, at the time of consenting to the examination. This would eliminate any possibility of distressing them with an unsolicited approach with information after the necropsy is completed.

In conclusion, on the evidence of our study, communication of the results of necropsies among pathologists, hospital clinicians, and general practitioners is currently inadequate. Communication with relatives is probably poor and contrasts with the evidence that discussion of necroscopic findings helps the grieving process. Our suggested improvements to the system are simple and inexpensive to implement and should be the subject of further audit. The pathologist in district $A$ has altered practice in his department in the light of the results of this audit. The effects of these changes should be re-evaluated after an interval.

The study was undertaken jointly with the Research Unit of the Royal College of Physicians as part of an MSc in community medicine at the London School of Hygiene and Tropical Medicine. We thank Dr Geoffrey Carroll and staff of the Health Services Research Unit and Dr Anthony Hopkin of the Research Unit of the Royal College of Physicians for advice in planning this study, and the general practitioners, hospital clinicians, pathologists, and, in particular, the relatives who completed our questionnaire. The Research Unit of the Royal College of Physicians is supported by the Wolfson and Welton Foundations, charitable donations, and the Department of Health

1 Royal College of Pathologists, Royal College of Physicians, and Royal College of Surgeons. Autopsy and audit. A report of a joint working party. London: of Surgeons. Autopsy and a

2 Underwood JCE, Cotton DWK, Stephenson TJ. Audit and necropsy. Lance $1989 ; \mathrm{i} ; 442$.

3 Goldman L, Sayson R, Robbins S, Cohn LH, Bettman M, Weisbery M. The value of autopsy in three medical eras. $N$ Engl F Med 1983;308:1000-5.

4 Friederici HH. Reflections on the postmortem audit. FAMA 1988;260:34615 Schned AR, Mogielnicki RP, Stauffer MA. A comprehensive qualit assessment program on the autopsy service. Am $\mathcal{F}$ Clin Pathol 1986;86: 133-8

6 Laissue JA, Aldermatt HJ, Zurcher B, Truniger B, Gebbers JO. The significance of the autopsy: evaluation of current autopsy results by the clinician. Schweiz Med Wochenschr 1986;116:130-4.

7 Chana J, Rhys-Maitland R, Hon P, Scott P, Thomas C. Who asks permission for an autopsy. I $R$ Coll Phys 1990;24:185-8.

8 Neville G. Notifying general practitioners about deaths in hospital: an audit. I R Coll Gen Pract 1987:37:496-7.

9 Royal College of Pathologists Accreditation Steering Committee. The Roya College of Pathologists United Kingdom pilot study of laboratory accreditation. I Clin Pathol 1990;43:89-92.

10 Cartwright A Hockey J, Anderson JL. Life before death. London and Boston: Routledge and Kegan Paul, 1973.

1 Cartwright A, Bowling A. Life after death. A study of the elderly widow. London and New York: Ta A. Lif afler death. A sudy ol

12 Brown HG. Lay perceptions of autopsy. Arch Pathol Lab Med 1983;108:446-8.

(Accepted 6 August 1991)

\section{MIRROR OF MEDICINE}

Lister's success was accelerated by a paper that his registrar, Watson Cheyne, published in the $B M F$. This provided a statistical analysis of Lister's operations since 1871 , and thereby supplied an omission, for Lister had frequently been criticised for failing to publish, and even of suppressing, statistics of his cases. As recently as August 1879 the fourna itself had observed "that there is something, we will not say suspicious, but at any rate strange, in the persistent avoidance of the challenge so often thrown out to $\mathrm{Mr}$ Lister and his followers to show, by actual comparison, whether, and if so, how far, their results are really superior to those of surgeons who do not admit their theory." Of Cheyne's account the fournal said: "The result shown is so marvellous a triumph over accidents known to be inseparable from a series of such operations till Lister robbed them of their danger, that they require no comment." They may have required no comment from the fournal, but they elicited comments aplenty from James Spence, who, as Professor of Surgery at Edinburgh University, had been a senior colleague of Lister's.

Motivated, it has been said, by envy, Spence launched "the last and bitterest attack against Lister" in the pages of the $B M \mathcal{F}$. In two papers entitled "Surgical statistics," Spence sought to show how his simpler methods of dressing were superior to those pioneered by Lister. His argument was comfortably refuted by both Lister and Cheyne, while the Fournal, in a later editorial, concluded that "the result of the discussion has only been to bring out in more striking contrast the imperfections of 'simple' methods of dressing in the hands of a most distinguished surgeon, when compared with the brilliant results of treatment conducted on strict Listerian principles." In a later letter Spence dismissed this leading article as "distorted" and complained that Hart had suppressed parts of his original text. Hart replied that he had cut only such "objectionable . . . acrimonious personal remarks" that were "scarcely worthy of so eminent a surgeon." On this note he decreed that the controversy should cease.

From Mirror of Medicine: A History of the BMF by P W J Bartrip. Published jointly by the $B M \mathcal{F}$ and Oxford University Press; BMA members' price UK $£ 29$, overseas $£ 33$, including postage Obtainable from the Publishing Manager, $B M \mathcal{F}$, PO Box 295, London WC1H 9TE. Non-members UK £35. Obtainable from OUP Distribution Services, Saxon Way West, Corby, Northamptonshire NN18 9ES 